\title{
Sudden activation of temporary cardiac pacing due to postoperative brainstem hematoma in 2 cases
}

\author{
Yuki Terada, Satoki Inoue* and Masahiko Kawaguchi
}

\section{To the Editor}

It has been noted that brainstem lesion surgery especially on the medulla oblongata may cause hemodynamic changes with transient acute bradycardia or asystole and hypotension during surgical procedures [1]. In one such case, temporary cardiac pacing (TCP) served as an effective option for preventing hemodynamic complications induced by surgical procedures [2]. Although TCP during this surgery occasionally activated when the heart rate dropped below the predefined threshold, surgery was not interrupted, and radical tumor removal was successful. We report 2 cases of hemangioblastomas in the cerebellopontine angle (CPA) with intraoperative courses identical to the above-mentioned case report where TCP was periodically activated post-surgery because of hematoma at the surgical lesions.

A 43-year-old man underwent surgical removal of a hemangioblastoma in the CPA and TCP was inserted on the day of surgery after anesthesia induction. The pacemaker was programmed to VVI mode at $50 \mathrm{bpm}$. During surgical manipulations, the TCP worked frequently and prevented interruption of the procedures. After $8 \mathrm{~h}$ of surgery, computed tomography (CT) of the head showed successful decompression but a small remaining tumor lesion. The patient was electively ventilated in the intensive care unit (ICU). One hour after admission to the ICU, the TCP suddenly activated and started pacing at $50 \mathrm{bpm}$, which had been set as the predefined threshold; the actual heart rate was approximately $20 \mathrm{bpm}$, which was confirmed by temporarily interrupting the pacing. An urgent head CT showed that a postoperative hematoma compressed the medulla oblongata (Fig. 1a). After surgical removal of the hematoma, the spontaneous heart rate stabilized. The patient remained ventilated for 3 days and then was weaned. The other postoperative course was uneventful although he required a ventriculoperitoneal shunt due to postoperative hydrocephalus. The second case was a 50-year-old man who also underwent surgical removal of hemangioblastoma in the CPA. Fifteen minutes after admission to the ICU, TCP was activated and started back-up pacing of VVI mode at $50 \mathrm{bpm}$. An urgent head CT showed postoperative hematoma (Fig. 1b) after which he followed a course similar to the previous case.

From the standpoint of neurosurgical procedures, TCP prevents procedure-induced bradycardia and hypotension and provides a satisfactory condition for tumor removal. Apart from surgical procedures, TCP is an actual lifesaving device for bradycardia. Additionally, TCP may serve as a warning monitor for postoperative hematoma associated with brainstem lesions including those of the medulla oblongata and may facilitate rapid surgical intervention if needed. It is well documented that hemangioblastomas are significantly correlated with an increased risk of a postoperative hematoma [3]. In cases of hemangioblastoma with brainstem lesions such as our 2 cases, TCP may be effective to prevent severe hypoperfusion during the postoperative period as well as during surgical manipulations.

\footnotetext{
* Correspondence: seninoue@naramed-u.ac.jp

Department of Anesthesiology and Division of Intensive Care, Nara Medical

University, 840 Shijo-cho Kashihara, Nara 634-8522, Japan
}

Springer Open (c) The Author(s). 2020 Open Access This article is licensed under a Creative Commons Attribution 4.0 International License which permits use, sharing, adaptation, distribution and reproduction in any medium or format, as long as you give appropriate credit to the original author(s) and the source, provide a link to the Creative Commons licence, and indicate if changes were made. The images or other third party material in this article are included in the article's Creative Commons licence, unless indicated otherwise in a credit line to the material. If material is not included in the article's Creative Commons licence and your intended use is not permitted by statutory regulation or exceeds the permitted use, you will need to obtain permission directly from the copyright holder. To view a copy of this licence, visit http://creativecommons.org/licenses/by/4.0/. 


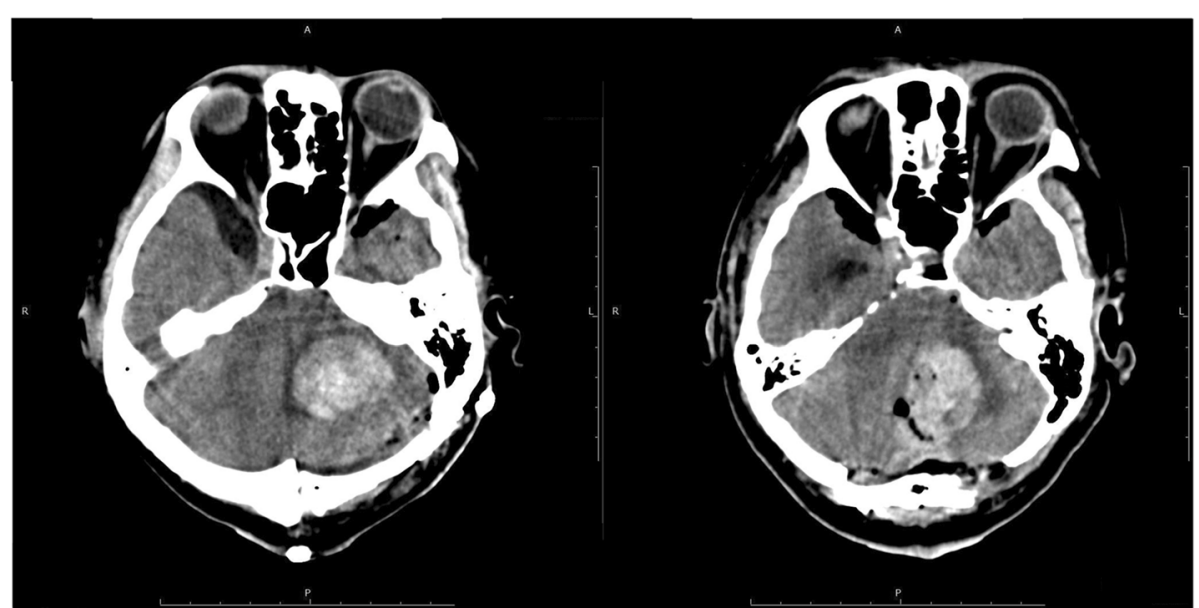

A

B

Fig. 1 Postoperative intracranial hematoma. Postoperative brain computed tomography showing intracranial hematoma. Hematoma in the left cerebellopontine angle in case 1 (a) and case 2 (b) was detected by postoperative bran computed tomography examined after the onset of bradycardia in the ICU

Abbreviations

TCP: Temporary cardiac pacing; CPA: Cerebellopontine angle; CT: Computed tomography; Wl: Ventricle paced, ventricle sensed, and pacing is inhibited if beat is sensed

\section{Acknowledgements}

The authors would like to thank ENAGO (www.enago.jp) for the English language review.

\section{Authors' contributions}

YT and SI collected, analyzed, and interpreted the patient data regarding the postoperative course. SI was a major contributor in writing the manuscript. MK reviewed and edited the manuscript. All authors read and approved the final manuscript.

\section{Funding}

This study was supported only by departmental funding from our institution.

Availability of data and materials

Not applicable

Ethics approval and consent to participate

Not applicable

\section{Consent for publication}

Consent to publish was obtained from that the patients. Our institutional review board approved to publish this case reports (No 885 June 25, 2014).

\section{Competing interests}

The authors declare having no competing interests.

Received: 1 August 2020 Accepted: 25 August 2020

Published online: 09 September 2020

\section{References}

1. Endo T, Sato K, Takahashi T, Kato M. Acute hypotension and bradycardia by medulla oblongata compression in spinal surgery. J Neurosurg Anesthesiol. 2001;13:310-3.

2. Della Puppa A, Rustemi O, Gioffrè G, Leoni L. Brainstem surgery assisted by temporary trans-venous pacing to prevent severe bradycardia. Acta Neurochir. 2014;156:431-2.
3. Kageji T, Nagahiro S, Mizobuchi Y, Nakajima K. Postoperative hematoma requiring recraniotomy in 1149 consecutive patients with intracranial tumors. Oper Neurosurg (Hagerstown). 2017;13:392-7.

\section{Publisher's Note}

Springer Nature remains neutral with regard to jurisdictional claims in published maps and institutional affiliations.

\section{Submit your manuscript to a SpringerOpen ${ }^{\circ}$ journal and benefit from:}

- Convenient online submission

Rigorous peer review

- Open access: articles freely available online

- High visibility within the field

- Retaining the copyright to your article

Submit your next manuscript at $\boldsymbol{\triangleright}$ springeropen.com 